Submission ID: 43826

\title{
Prospects of the Construction Regional Seismic 3D Cubes with Data of 2D
} Seismic Exploration

A.Z. Nedostupov* (Geostra Research and Production Center, LLC), T.R. Sharafutdinov (SPC Geostra LLC), I.A. Mushin (FSBI VNIGNI)

\section{SUMMARY}

At the level of the modern study of the Russian Federation by seismic exploration there are still gigantic poorly studied territories such as Taimyr which still remains the least explored region of Russia in regard to geology. Solving the problems of zoning with traditional methods requires huge financial investments and, along with this, considerable time. Solving the problems of zoning with traditional methods requires huge financial investments and, along with this, considerable time. Therefore, innovative technologies, which help to reduce the time and economic costs for solving these problems, acquire special relevance recently.

After heterogeneous priori G\&G data are converted to a predicted 3D seismic wave field we have succeeded to discover vast opportunities to identify and oil-and-gas bearing features both earlier known in oil and gasbearing area and new which have been not revealed and researched yet. 
Перспективы построения региональных 3D кубов по данным 2D сейсморазведки

А.3. Недоступов* (ООО НПЦ «Геостра»), Т.Р. Шарафутдинов (ООО НПЦ «Геостра»), И.А. Мушин (ФГБУ «ВНИГНИ»)

\section{Введение}

На фоне детально изученных сейсморазведочными работами нефтегазоносных областей РФ, остаются слабоизученными такие территории, как Таймырский полуостров, который по настоящее время в геологическом отношении является одним из наименее изученных регионов России.

Таймырский муниципальный район Красноярского края полностью находится за Полярным кругом, и даже в масштабах всей России выглядит вполне солидно, охватывая огромную территорию в 884 тыс. кв. км. Из-за большой удаленности и слабо развитой инфраструктуры Таймыр остается в геологическом отношении наименее изученным регионом России.

Сейсморазведочные работы ведутся здесь многими компаниями на протяжении многих десятков лет XX и XXI в. Основной объем полевых сейсморазведочных работ на Таймырском полуострове, особенно в последнее время, приходится на компанию АО "Башнефтегеофизика" в лице ее дочернего предприятия АО “Таймыргеофизика", Доминирующее положение в области обработки и интерпретации сейсморазведочных данных по Таймырскому полуострову так же принадлежит АО “Башнефтегеофизика” в лице дочернего предприятия ООО НПЦ “Геостра".

Решение геологических задач здесь традиционными методами требует огромных финансовых вложений и, наряду с этим, значительного времени. Поэтому особую актуальность в последнее время приобретают инновационные технологии, способствующие сокращению времени и экономических затрат на решение этих задач. В работе рассмотрены основные возможности и перспективы технологии построения региональных 3D кубов на основе 2D сейсмических профилей. После трансформации разнородной априорной геолого-геофизической информации в прогнозное объемное сейсмическое волновое поле удалось открыть огромные возможности по выявлению и локализации нефтегазоносных объектов как ранее известных, так и новых, пока еще не выявленных и неизученных.

\section{Метод}

Сейсморазведка 3D стандартно применяется на разведочных, а в настоящее время уже и на поисковых этапах ГРР. Теперь на очереди освоение регионального этапа ГРР. Актуальность этого обусловлена тем, что традиционные для регионального этапа ГРР сейсмогеологические разрезы, двумерные схемы и карты, содержащие, главным образом, представления о структурно-тектоническом строении границ крупных осадочных комплексов, явно недостаточны для поиска новых локальных залежей углеводородов.

Региональная модель должна быть объемной, поскольку изучению подлежат:

- объемные геологическая среда и объекты,

- $\quad$ не только морфология и мощности осадочных комплексов, но и их внутренняя структура, формационный (вещественный) состав и емкостные свойства. 
Построение объемных геологических моделей (сейсмических кубов) по слабоизученным осадочным бассейнам на основе крайне неплотных и, как правило, нерегулярных сетей региональных сейсмических профилей, изначально представляется мало реальной задачей. Действительно, при достигаемой на практике плотности региональных сейсмических наблюдений не может быть и речи об их интерполяции и экстраполяции. Следовательно, задача не может быть решена стандартными техническими средствами.

При этом принципиально важно, что на самих региональных сейсмических профилях, как правило, достигается детальность наблюдений, не ниже чем при поисковоразведочных работах. Ясно, что идеальным решением задачи было бы распространение этой детальности на всю территорию исследуемого нефтегазоносного бассейна (НГБ).

К настоящему времени на основе интеграции методологий седиментационноемкостного моделирования (CEM) и сейсмоформационного прогнозирования (СФП) создана инновационная технология региональной сейсморазведки «РегионСейс-3D», разработанная в ФГБУ «ВНИГНИ» [3].

Технология прошла апробацию и внедрение в 5 НГО Лено-Тунгусской НГП, наиболее изученных сейсморазведкой и бурением. В пределах этих НГО находятся крупные и уникальные месторождения в рифейском, вендском, венд-нижнекембрийском и нижнекембрийском нефтегазоносных комплексах, - такие месторождения, как Юрубченское, Куюмбинское, Верхнечонское, Талаканское, Чаяндинское, Ковыктинское, Левобережное и др. Все эти месторождения нашли свое отображение на прогнозных кубах. Кроме того, выявлены и новые объекты, по которым в настоящее время проектируются поисково-разведочные работы.

Технология апробирована также в «Совете по геофизическим работам на нефть и газ при Федеральном Агентстве «Роснедра».

В ООО НПЦ «Геостра» технология нашла свое применение в Гыданской, УстьЕнисейской нефтегазоносных областях и на одном из участков в Башкортостане.

\section{Результаты}

B работе описаны перспективы применения технологии «РегионСейс-3D» на УстьЕнисейской нефтегазоносной области на Таймыре.

Редкая сеть 2D сейсмических профилей с низкой плотностью накладывает ограничение на получение достоверных данных о геологии и не может дать однозначного ответа на вопрос: насколько точна итоговая объемная геологическая модель в межпрофильном пространстве? Именно поэтому для уточнения геологического строения среды при дефиците геолого-геофизической информации можно воспользоваться возможностями технологии «РегионСейс-3D» [3] для построения региональных сейсмических 3D кубов на основе 2D сейсмических профилей.

На рисунке 1 представлен прогнозный псевдокуб 3D, построенный на основе сейсмических профилей 2D МОГТ. 


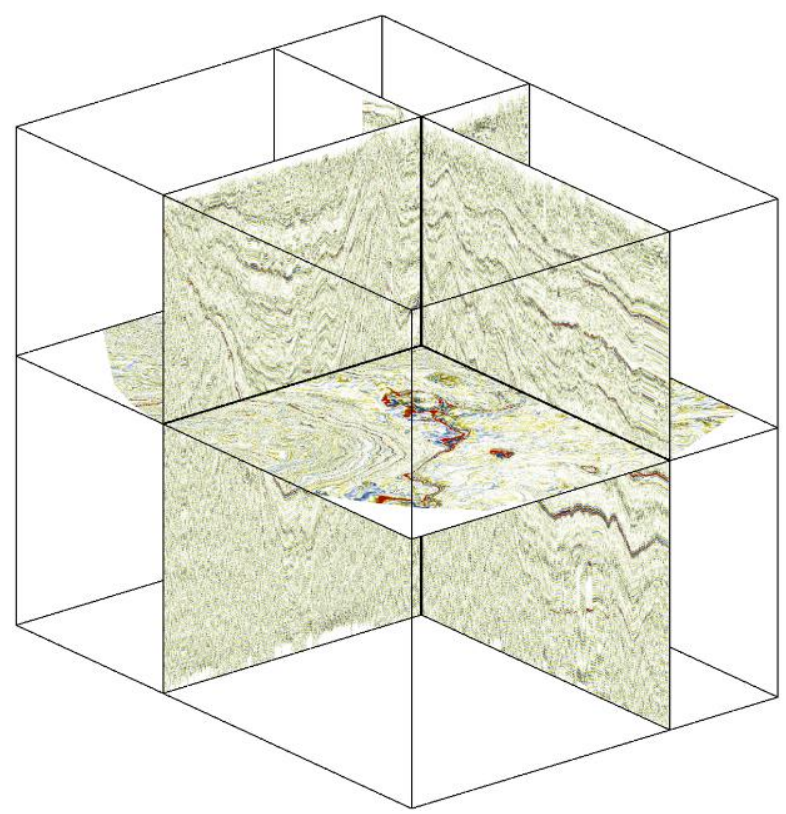

Рисунок 1 Пример прогнозного псевдокуба 3D

Анализ прогнозного куба 3D обеспечивает большой прирост информации. К примеру, удается выделить интересные объекты в межпрофильном пространстве, оконтурить области с повышенной степенью коллекторских свойств и т.п. (Рис.2).

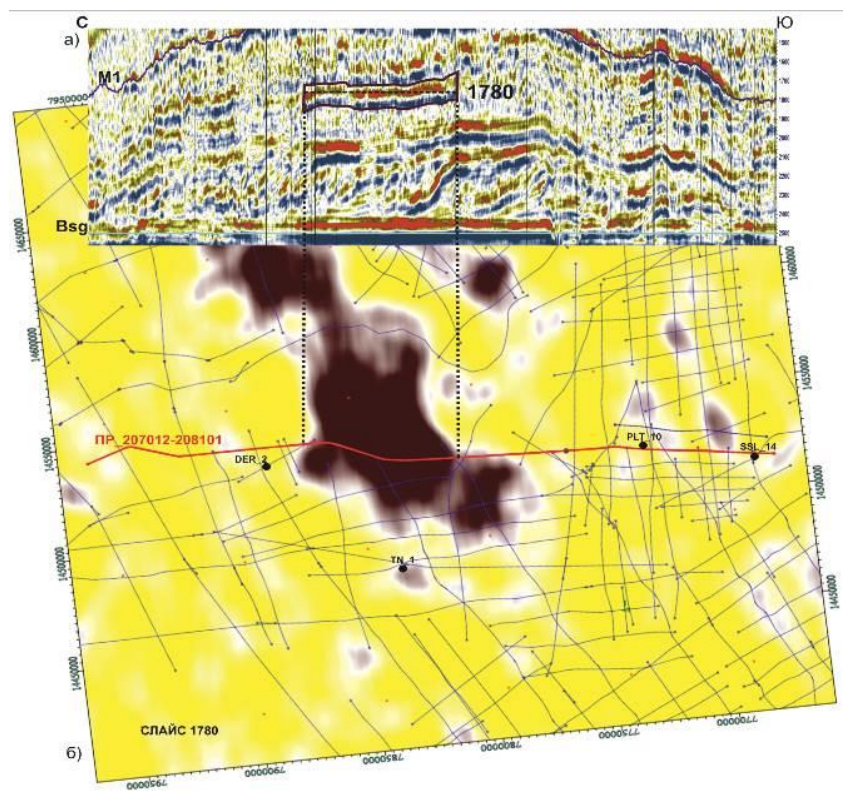

Рисунок 2 Выделение сиквенсов по фрагменту профиля 2D и сопоставление со слайсом палеокуба, пересчитанного в атрибут, отражающий повышенные коллекторские свойства

При получении прогнозного куба 3D в Усть-Енисейской нефтегазоносной области главное внимание было уделено изучению возможностей выявления и локализации нефтегазоносных объектов как ранее известных по НГО, так и новых, пока что не выявленных и неизученных. 
Именно ответ на этот вопрос по существу предопределяет главное решение о практической целесообразности построения региональных сейсмогеологических кубов.

\section{Выводы}

Использование объемных данных, обеспечивает оптимизацию планирования новых работ - региональных и поисковых, опережающих процесс медленного, дорогостоящего и, как правило, слабо обоснованного наращивания сейсмической информации по региону.

В процессе работ существенно расширился ассортимент разнообразных факторов, обуславливающих необходимость перестроения прогнозного куба, в числе которых:

- появление новых (дополнительных) материалов и данных, учет которых при построении куба представляется обязательным;

- выявление после построения куба некоторых особенностей строения разреза, требующих его перестроения;

- постоянное совершенствование технологии и методики «РегионСейс3D», обуславливающее необходимость перестроения куба с целью повышения его качества и надежности и т.п.

Бесспорно, вовлечение в обработку данных по обширным территориям (НГП) позволит кратно увеличить эффективность геологоразведочного процесса. Также, возможность накопления и обновления 3Д-объемной информации придает геологоразведочному процессу осмысленный и взаимоувязанный по разнородным (по времени исполнения) материалам характер.

В качестве заключения, хочется подытожить ответом на вопрос: какие же возможности дает нам построение и использование прогнозных кубов 3Д, полученных на основе сети профилей 2D МОГТ? Оно состоит в возможности выявлять и анализировать в объемных сейсмических отображениях, причем целиком, - крупнейшие элементы геологического строения изучаемых территорий: сводов, седловин, впадин, рифтов, систем тектонических нарушений разного ранга, барьерных рифовых систем, а также уникальных и крупных мест скоплений УВ и их ареалов. И эта информация обязательно привнесет свой существенный вклад в открытие новых перспективных объектов с залежами углеводородного сырья на территории Российской Федерации.

\section{Литература}

1. Воскресенский Ю.Н. Изучение изменений амплитуд сейсмических отражений для поисков и разведки залежей углеводородов: Учебное пособие: РГУ нефти и газа им. И.М. Губкина. 2001.

2. Копилевич Е.А., Афанасьев М.Л. «Новые возможности геологической интерпретации данных сейсморазведки». Геология нефти и газа, №5, М., 2007.

3. Мушин И.А., Фортунатова Н.К., Белоусов Г.А. «Технологии построения объемных седиментационно-емкостных моделей осадочных бассейнов». Технологии сейсморазведки, №1, 2012. 


\section{EAGE}

\section{References}

1. Voskresensky Y.N. Izuchenie izmenenii amplitud seismicheskih otraghenii dlya poiskov i razvedki zaleghei uglevodorodov [The study of changes in the amplitudes of seismic reflections for prospecting and exploration of hydrocarbon deposits]. Tutorial. Gubkin University. 2001.

2. Kopilevich E.A., Afanasiev M.L. Novie vozmoghnosti geologicheskoi interpretacii dannih seismorazvedki [New opportunities for geological interpretation of seismic data]. Geology of oil and gas, №5, M., 2007.

3. Mushin I.A., Fortunatova N.K., Belousov G.A. Tehnologii postroeniya obiemnih sedimentacionno-emkostnih modelei osadochnih basseinov [Technologies of construction of the volume sediment-capacity models of sedimentary basins]. Seismic survey technology, №1, 2012. 